\title{
Interactive Television in Schools: An Australian Study of the Tensions of Educational Technology and Change
}

\author{
Terry Evans \\ Elizabeth Stacey \\ Karen Tregenza
}

\begin{abstract}
This paper outlines some key issues that arose from several projects that investigated the use of interactive television in schooling. In this paper we draw on these projects, to illustrate and discuss how a (then) new form of distance education - satellite-based, narrowcast ITV - was designated for use in primary (elementary) and secondary (high school) classroom settings, how it was implemented, and how it collapsed as an endeavour. Issues raised by students, teachers and administrators are related to each to illustrate how ITV slowly declined over several years, despite its usefulness for some and strong support from those involved.
\end{abstract}

\section{Introduction}

The origins, changes and use of interactive television (ITV) in the school system in the State of Victoria, Australia have been studied by the authors for over 8 years through 3 different research projects. Two projects were funded by the Australian Research Council (ARC) and one by Deakin University ${ }^{1}$. They provided a perspective on the interrelationships between changes to government policy, changes to an educational technology and the consequences for schools (see Evans, Stacey \& Tregenza, 1999a, 1999b, 1999c, 1999d, 2000a, 2000b; Evans \& Tregenza, 1993, 1996a, 1996b). In this article we draw on these projects, especially on the final and largest study, to illustrate and discuss how a (then) new form of distance education - satellite-based, 'narrowcast' ITV - was designated for use in primary (elementary) and secondary (high school) classroom settings, how it was implemented, and how it collapsed as an endeavour. The issues raised by students, teachers and administrators are counterposed with each other to show how a potential innovation gradually sank with hardly a ripple. The ways in which the authors were drawn into the politics of the sinking are discussed. 
Interactive Television in Schools: An Australian Study of the Tensions of Educational Technology and Change

\section{Context}

Victoria is the second most populous (about four million people) and second smallest in area (about the size of Britain) of the Australian states. It has a significant rural population and some isolated communities. The first correspondence schooling in Australia commenced in Victoria, and schooling through distance education continues until today, although it is the other mainland states and the Northern Territory, with their far more remote and vast spaces, which retain a stronger profile in schooling at a distance, particularly through the Schools of the Air. The use of satellite, cable and, increasingly, digitised forms of ITV broadcasting and "narrowcasting" has become an important feature of distance schooling in countries where geography, demography and/or climate make it difficult to provide efficient traditional schooling across the range of curricula required of schools. Canada and Scandinavia are two other examples of ITV being significant in schooling (Haughey \& Roberts, 1996; Meisalo, 1996). In Australia, Victoria's SOFNet (Schools of the Future Network) is arguably the most widespread system-wide ITV provision of any similar school system in the world (Aliani, 1995).

The origins of the use of ITV in the school sector in Victoria go back to 1992. The Labor (centre-left) government's Directorate of School Education (DSE) provided two professional development courses for teachers through 88 postprimary and Technical and Further Education colleges in regional and rural areas using satellite transmitted interactive television (ITV). Programs consisted of live one-way television transmission with the interaction sustained by live telephone link, or delayed fax. ITV was a marked change from the usual approach to the professional development of teachers in Victoria which was (and mostly is) usually completed either during school hours, professional development days or during evenings, weekends and holidays. The potential time and cost reduction of using ITV, especially for country teachers and schools, was seen as substantial.

In 1993 the Labor Government lost office in a landslide election to a Liberal - National Party (centre-right) coalition. The new government had a strong reform agenda which was congruent in style and intended outcomes with many, especially right-leaning, Western governments. Schooling was an important area for reform for this Government. Its goals were to reduce costs, reduce the influence of the unions, increase accountability measures, and refocus the curricula and the testing and assessment systems. Perhaps contradictorily, the new government also sought to centralise political and bureaucratic control over schools, whilst simultaneously devolving more responsibilities to them (including budgets).

The Coalition Government's policy for school reform was entitled Schools of the Future and it served as a counterpoint to the less rosy actions it was taking. Within its first months the stage was set for massive staff reductions (in

International Review of Research in Open and Distance Learning 
teaching, support and regional administrative positions) together with school closures and amalgamations. These cuts to the education budget were said to be necessary to help reduce state debt, and to provide the capacity to reorganise schools and equip them with new technology, hence, build the Schools of the Future. As part of this future, the Minister of Education decided that ITV would be expanded into a statewide network for all government schools, with non-government schools being invited to join. Schools were provided with a satellite receiving dish, decoder and wiring to one room. It was decreed that the system would now be titled 'SOFNet', which stood for 'Schools of the Future Network'.

Significantly, SOFNet programs were to be vastly expanded to have a central role in providing teaching and support for key curriculum areas, and also for the dissemination of 'corporate' information, alongside its original professional development brief. In an unrelated part of the Schools of the Future policy, the Government issued directives that at least one Language Other Than English (LOTE) be offered in primary schools, and at least two in secondary schools. It also required a boost in the level of science and technology studies, and a revised Victorian Certificate of Education (VCE - Year/Grade 11 and 12 assessment) was introduced. As there were considerable shortages of teachers qualified to teach in the LOTE, science and technology areas, especially in rural and remote schools, SOFNet was marshalled to support these directives. Hence, its mandate to offer teaching and support for these key curriculum areas came to dominate the transmission times and program resources although other programs were produced on particular subjects, such as on welfare and career matters.

By 1997, the Department of Education (the Coalition Government renamed the DSE the DoE - in Australia it is common for new governments to rename their departments, despite the costs and disruption involved) was reporting that 600 hours of programs were broadcast, 2,500 schools participated and an estimated 100,000 students learned another language via SOFNet (Victorian Department of Education, 1997). The main program series were Science and Technology Education in Primary Schools (STEPS) and Primary Access to Languages via Satellite (PALS). These two programs dominated the transmissions, especially PALS as it had different transmissions for the languages it covered: Italian, Indonesian, Mandarin, Japanese, French and German. Similar secondary programs, SALS (Secondary Access to Languages via Satellite), were also developed.

Until 1998 students from anywhere in Victoria, and from a few ITV-connected schools in South Australia and New South Wales, were able to participate in each program live-to-air. They talked by phone with the teacher (presenter) in the studio. Somewhat contentiously, as is explained later, after 1998 the opportunities to interact were ceased or greatly curtailed to the extent that SOFNet became more of a video distribution network for schools to record their own video-cassettes of the programs.

International Review of Research in Open and Distance Learning 
Alongside the programs delivered by SOFNet, participating schools received comprehensive materials comprising a list of resources required for each program, the expected student outcomes, a brief summary of the program format, and detailed descriptions of the activities to be undertaken. The interactive programs were either weekly or fortnightly, and of 30 minutes or 1 hour duration, depending on curriculum area and the year level. Typically, teachers were expected to prepare for each program, and to have their students complete work and activities before and/or afterwards. By 2000 there was an increasing use of e-mail and of a SOFNet Web site to complement and enhance the programs.

From the outset when ITV was first seen as a professional development medium for teachers in rural and remote schools, the intention was that other members of the community could use the facilities outside of schools' transmission times. Therefore, some community, professional and government organisations used the ITV system for either special individual programs, or even series. Examples are programs on matters of public health for community health staff, or on mandatory reporting of child-abuse for teachers, child-care workers, and health professionals. ITV was also used for special schools programs. A good example is the "Communicating over the Catchment" programs that were transmitted annually for 3 years. The programs were a form of student conference around conservation and environmental issues, principally focused on the Murray-Darling River basin. Each year it was developed and broadcast live from Melbourne Zoo with support from the Murray-Darling Basin Commission. The program consisted of 2, 1 hour programs about conservation issues, using students' activities and school locations. It provided students with the capacity to interact live with zoo experts via telephone, fax, e-mail or Web Chat.

\section{Research Plan}

As was noted in the introduction, this article draws mainly on an ARC Large Grant research project conducted by the authors from early 1998 to late 2000. The research aims included:

- To investigate, record and analyse, the use of ITV in primary and secondary schools, especially in terms of the development of interactive and dialogic approaches to teaching and learning.

- To study the processes through which teachers and students adopt, and adapt to, the interactive and dialogic elements of ITV.

- The research used qualitative research methods to develop case studies of the implementation and use of ITV in selected schools. The criteria for selection in 1998 and 1999 included being a regular, 'live' SOFNet user, although some of the case-study sites did use a mixture of both live and 
Interactive Television in Schools: An Australian Study of the Tensions of Educational Technology and Change

taped programs. The 2000 fieldwork focused on the use of videotaped programs, although covering live programs (usually professional development) where offered. ${ }^{2}$

The case studies involved the use of several different methods, from the collection, collation and analysis of documents, through interviewing of key informants, to observations of ITV lessons in schools, meetings and ITV production sites. Using the transcriptions of observations and interviews, together with the other material collected, the data were reviewed to identify key themes that emerged, and organised using the Non-numerical Unstructured Data Indexing, Searching and Theorising (NUDIST) qualitative data analysis software.

The first phase of the research in 1998 involved the selection of seven primary schools, five Victorian and two interstate primary schools, each being from either a country, regional or metropolitan region. Two were non-government schools. Each primary school ITV case study was conducted simultaneously and, where possible, covered the STEPS and PALS programs. Throughout the year teachers were invited to discuss the children's learning through ITV, as well as their own experiences of teaching with, and alongside, ITV. Typically, the ITV broadcasts were only part of the timetable for the particular curriculum area and the teachers worked with the children 'off-air' in other timetabled sessions. Selections of these lessons were also observed in addition to the actual ITV broadcast sessions that were watched, either live by the class, or taped and played back at another time.

The second phase of the research in 1999 involved six Victorian and one interstate secondary school. The curriculum areas selected for study at these schools again were chosen from those offered to secondary schools via ITV. In addition to the specific focus on the case studies, a sample was also made of other uses of ITV in the schools and by the Department of Education.

The research also extended into 2000, principally because the shift to video use was occurring and this was seen to be of significance. This involved follow-up work in the schools covered in 1998 and 1999, plus one new primary school and two new secondary school case studies which became involved in using SOFNet. We studied a total of 17 schools using SOFNet out of 98 registered 'users'.

\section{Research Overview}

A total of 123 SOFNet participants were interviewed for this research project. This included: (a) 25 teachers; (b) 95 students ranging from Grade 1 to Year 11 (individual and group interviews); (c) two program developers/presenters and (d) one Department of Education manager. Over 60 site-visits were made for classroom observations and other fieldwork, together with visits to pre and/or post program classroom sessions, production sites and so forth. It was during

International Review of Research in Open and Distance Learning 
the school visits that teachers raised many administrative issues that inhibited or limited their use of SOFNet. The most prevalent factors were program scheduling and school timetables that dictated whether SOFNet was adopted in schools. These factors consequently posed problems in conducting the research, especially around scheduling observations of SOFNet classes.

A major factor contributing to schools' difficulties in adopting SOFNet was the insufficient period of notice of program schedules and content and the flexibility of schools' approaches to ITV affected each SOFNet program's effectiveness. If a program could not be scheduled easily into a school timetable or there was inflexibility in the manner and timing of the school's viewing of the program, classroom teachers could not always access the live and taped broadcasts to suit the children's learning, and could not customise the programs to fit their circumstances. This was particularly a problem in the secondary schools where the timetables were more rigid and often led to programs being taped for later use. In secondary schools, programming schedules are required well before the next year's timetable is set. In primary schools, program content details are required well before the term's curriculum is planned so that not only can the SOFNet programs be scheduled, but also so they can be integrated into the curriculum in a meaningful way. The teachers' use of the program notes in their curriculum planning depended on their receiving this information well ahead to allow long term planning. The normal SOFNet scheduled procedures (a fortnightly program schedule publicised in the Education Department's newspaper, Education Times) were inadequate in these respects, often resulting in the teacher's deciding not to participate.

Even the normal schedule procedures were not always adhered to, consequently program information and materials arrived so late as to render the schools' use of programs ineffective. For example, information and materials for the interactive Horizons programs for gifted students were received either the day before, or on the day the program was to be broadcast. On occasion, some programs were never publicised at all. While other programs provided information 2 weeks in advance, teachers felt this too was inadequate. Teachers thought that, as had happened in 2000, delivering resources electronically would increase the notice. However, it seemed that the time saved by online distribution of information about schedules and special programs was used by the program administrators to ease their schedules. As they no longer had to allow for possible postal delays, schools received notices even later! In some instances, special programs were so poorly publicised that schools were not even aware that they existed until the research team contacted them to see if they intended using the program. Due to the research team's regular contacts with the program-makers and administrators, it was often the case that the team would be providing advanced notice of forthcoming SOFNet programs, content and timing. This had the effect of influencing the nature of the research and potentially its outcomes. It was clear that, in some instances, schools were able to be observed only because they chose to view a program on the basis of information we provided in the course 
Interactive Television in Schools: An Australian Study of the Tensions of Educational Technology and Change

of establishing if they were likely to use that forthcoming program.

As noted previously, ITV broadcast sessions and pre and/or post lessons were observed by the research team. When two or more case study schools were using the same program live, often doing the pre/post activities immediately before and after broadcasts, the team endeavoured to cover all the sites so that comparisons could be made later by the researchers. Generally, however, single observations were made and recorded by either hand-written or laptop written notes which were then fully written later and subsequently coded as described below.

\section{Overview of the findings}

The researchers offered to provide a confidential summary of findings to each school that was tailored for them. In addition, similar tailored summaries were offered to program makers and the managerial team for SOFNet. As a result the research team was also invited to present a summary to some of the key government bureaucrats responsible for educational technologies (Evans et al., 2000a). During the course of these presentations the key issues involved in the operation of SOFNet were discussed, as were the issues involved if it were to continue. We present an overview of two main issues, interaction and the shift to video, before outlining additional points we conveyed to the participants. Although our research was not an evaluation, it yielded some findings that served a similar purpose. It was considered that the sharing of such findings with the research participants was a way of ensuring that they benefited from the research as well as the researchers and the scholarly and educational communities more generally.

\section{Interaction}

The interactive elements of the SOFNet programs were valued as central to the use of ITV by the teachers and children, and to the program makers and SOFNet management. In order to manage the numbers of live-to-air interactions, typically a few schools would be nominated to interact for a particular program. This would be done in advance so that the teachers could make the necessary arrangements for children to use a phone in an adjoining office or a mobile phone away from the classroom to prevent acoustic feedback. The interactive elements took many forms. They could be live-to-air question and answer sessions between children and the program presenters, for example in a LOTE area where matters of pronunciation were important. Or they could be tasks for the children to do which they would then fax to the program makers and discuss with them by phone. All schools would be encouraged to interact 'off line' so, for example, comments on other schools faxed work, or on e-mail 
Interactive Television in Schools: An Australian Study of the Tensions of Educational Technology and Change

queries, and so forth, would be provided on-air in the next program. The intention being that to mention a school and a child on air would encourage the interactive participation in the program.

When schools were able to participate, interaction became an important part of the learning process for the students and an important professional tool for the teachers. For students, interactive points in the programs were particularly motivational and provided a pacing mechanism for their learning. The interactive elements encouraged all students to enter into a dialogic process within the class. Students generally focused intensely on the ITV interaction and the motivation of preparing a response improves the importance and quality of the shared experience. In both secondary and primary classrooms it was a motivational highlight for the children to talk to the presenters and to be an audible part of the satellite transmission or to fax questions or class work during or after the program and to have it acknowledged by the presenters subsequently.

For teachers, particularly in rural schools, it was a chance to see how other teachers and children interpreted the lessons and to see from another teacher's viewpoint if they were proceeding appropriately. In languages particularly, the program served as a model for correct pronunciation to teachers. These were not qualified LOTE teachers, indeed, with few exceptions, the teachers also had no prior experience in either speaking the particular language. Some of the teachers we observed had developed a considerable facility in the LOTE being taught and this was all due to them using the ITV programs and resources over a few years. A few had also decided to undertake further study in the particular language mainly because they had become intrinsically interested in it, not merely to enhance their skills.

The interactive elements of SOFNet helped create a sense of community amongst the participating schools. There were instances of teachers contacting other teachers they had 'met' through SOFNet programs. This new community or network was particularly valued by rural schools who see themselves as isolated from the mutual benefits that suburban schools enjoy by working together on educational, sporting and cultural activities. The opportunity to have a window on other schools was also sustained by the program makers who often used schools as locations to shoot particular scenes for programs. Hence, interaction and dialogue becomes located socially and geographically for the persons involved and is not merely about squirting stimuli-responses back and forth via cable or satellite.

The regular interactive broadcasting of the programs provided momentum for keeping pace with the sequence of the syllabus and not letting other factors interfere with planning and timetabling. Teachers found that, as the interaction declined, especially by 2000 , it became easier to skip programs and then fall behind the necessary pace to cover the required learning in a term.

A common comment made in the students' interviews was that they liked watch-

International Review of Research in Open and Distance Learning 
ing and hearing other children interact. They participated in a form of vicarious interaction themselves when others were involved. Our classroom observations bore this out, as it was often noted that the students' attention was more focused on the program when interaction was occurring, than when it was not. Of course, when their school was nominated to interact live the excitement was palpable in the primary schools, and even secondary students exhibited heightened interest. The most common recommendation made by secondary and primary students was the involvement of school students in all programs, both through location shoots in schools and especially through interactive elements in programs. A Grade 6 metropolitan student noted that, '(i)t's easier for us to learn when they do it with other students...because they ask questions and they do the same things we would do if we were there.' Even secondary students responded positively to the interactive element because they could ask questions on the spot and the answers had the credibility of seeming honest. They showed a cynicism about mainstream broadcast television saying that with ITV they didn't use 'media manipulation' in answering as the presenter 'always gave them what he knew or thought, not what people wanted to hear.'

\section{Video-recorded programs}

Due to the administrative problems and the timetabling difficulties which larger schools experienced, it was very difficult to sustain even a modest number of schools using the programs in the interactive way that they were designed. Instead of addressing these problems, SOFNet as an interactive classroom curriculum provider was put into a slow glide toward oblivion. During late 1999 and into 2000 there was a gradual reduction in both interactive segments and school location shoots, also live programs were removed and replaced with tapes of previous programs. By 2000 plans were afoot to turn the live SOFNet programs into taped programs that would be transmitted for schools to record. However, even during the shift away from live and interactive programs, where the difficulties of administration might be expected to be greater, the administration was seen by the teachers to be as inefficient. Teachers complained that particularly the STEPS program notes had continued to be too late for effective planning (arriving in the last week of the preceding term). Though PALS materials did arrive on time, the program did not always match the notes received which meant that the essence of the lesson could be lost because the teacher and students could not follow the content as they had no vocabulary to consult. Teachers were frustrated that they could not plan their curriculum adequately, budget for materials for Science activities and, in the case of the Horizon programs, the lateness of detail meant no preparation could be done at all and the lessons could not be integrated into the school program in any meaningful way.

Contrary to what teachers had been led to believe would be the case, in the video programs STEPS did not incorporate students' work and had little video 
Interactive Television in Schools: An Australian Study of the Tensions of

footage in schools or with promised student involvement in other forms replacing the interactive elements. Though the PALS programs allowed for flexible timing and review as anticipated, the teachers thought the quality of the programs on video had deteriorated and was repetitive of earlier programs with the teachers having to edit them for class use. Students had lost interest and were bored with the programs with the interactive element removed, as without the network of communicating schools and presenters, the activities seemed lacking in authentic 'real world' purpose. Teachers thought that few newcomers to SOFNet would persist with the programs in their new format.

These difficulties were of less concern in the secondary schools, as they had often used some or all the programs by video recording as a way of overcoming timetabling difficulties. A new series of science programs called TREK was designed with no interactive elements and was well received by students. However, the interactive Horizons programs, despite their lower production values than the TREK programs, seemed to provide an immediacy and a currency in its curriculum elements which the students responded to with enthusiasm. The secondary students expected a Web presence for programs such as these and were keen to follow-up particular programs researching via a designed Website with links to other useful and relevant sites. Secondary school students recognised the potential of e-mailing questions to the expert guests and program presenters as perhaps being more efficient than phone interaction.

The programs had met criteria for effective television and video (Bates, 1984; Crooks, 1990; McMillan, 1994) including clear communication of the purpose and intent of each program; a familiar program structure presented by enthusiastic and plausible presenters who personalise the medium for the student audience; as well as designed active engagement of the students in their learning, such as through the interactive activities, and appeared to be providing a resource with localised content and presenters that was a welcome addition to the secondary curriculum.

\section{Summary of points additional to those above as they were communicated to the participants}

\section{Positive experiences}

- An improved quality of both the STEPS and LOTE programs over their years of production was noted.

- Accompanying written resources of great benefit to designing an integrated curriculum particularly in the primary sector.

- Many teachers only achieved their LOTE language skills through the SOFNet programs and they acknowledged the value of the PALS program as a means of such professional development.

International Review of Research in Open and Distance Learning 
- SOFNet programs were particularly useful to the rural and remote schools who had less access to active learning resources like excursions to museums, galleries etc.

- The students commented on the stimulation of learning through ITV. They often found the SOFNet programs more interesting than their traditional classroom lessons.

- The pace and visual impact of the live television programs typically captured the students' attention to a degree that their teachers found difficult to sustain themselves.

- Interactive questioning of expert guests who provided them with feedback was valued by all students whatever the content of the program.

Both teachers and students spoke of the medium catering to visual and aural learners. Poorer readers and younger children who do not read as competently can learn more effectively from this visual medium.

Secondary students, who were able to reflect more articulately about their learning through SOFNet, had perceived that they learned well from a visual medium. Varying the medium and process or style of learning caters to a range of students' learning styles compared with a text based secondary curriculum.

Both primary and secondary students valued the active learning which often accompanied SOFNet programs and if they were involved in small group active learning as part of the program they learned effectively.

\section{Negative experiences}

- Many of the negative comments were about the first (pre-SOFNet) programs. Many of the schools contacted, who no longer used ITV, cited one of the main reasons as the poor quality of the programs.

- In both primary and secondary classrooms students seemed to find the pace of the PALS and SALS programs too fast and the level of vocabulary introduction too difficult for them. Though the teachers spoke about the motivating aspect of the programs, the students talked of not understanding anything other than the occasional word. The immersion method of continually speaking the language being learned seemed to be too difficult for the both primary and secondary students and the primary teachers often had to translate for their students. Though these problems were responded to after teacher feedback; this continued to be a problem for many students.

- Worksheets supporting the SALS (secondary) programs were considered repetitive and uninteresting by the students.

International Review of Research in Open and Distance Learning 
The demands of the 'crowded curriculum' also affected the adoption of SOFNet, particularly in the primary schools.

Assessment - there was no formal assessment of student performance after PALS, SALS or STEPS in any of the schools though teachers were aware of students' capabilities in an informal way. However, there did seem to be an overall view that after a few years of language learning via ITV, progress was made and when they reached high school the outcomes were obvious in students' initial competence in language classes. However when questioned most children professed to knowing little and being unable to hold a real conversation with a native (fast) speaker.

By presenting our research to the participants it enabled them to recognise that there were no absolute answers to the question of whether SOFNet was viable and effective or not. The answer rather depended on the viewpoint which one adopted to 'read' the results. For the schools, typically they recognised the positives and wanted someone to fix the negatives or as many of them as possible. Their view was that they wanted SOFNet to continue and be improved. The program makers usually took a positive view too, although their perception of some of the negatives was rather different because they were responsible for them. However, their solutions to the negatives often abraded with some of the positives, especially those concerned with the value of interactivity. The managers viewed it differently again and were more inclined to fix the negatives by abandoning SOFNet entirely. This view had emerged previously in our project as we explain below.

\section{Concluding comment}

The research demonstrated that if one took a qualitative 'insider's' view of the experience of SOFNet, that is an active-user school's view, then the conclusion would be that ITV was a viable and effective medium for use in schools. This would be especially the case in primary schools, even more so for remote or rural schools. However, the difficulties the researchers had in selecting schools to observe, demonstrated that for most schools SOFNet was barely a consideration. For some it was used as a resource, but not as an interactive medium. Very few actually used it in the way it was intended.

We identified during the research that the management in the Department of Education was becoming concerned about the low level of use of SOFNet and the negative responses from schools. This became a big concern for those who were involved in running SOFNet because they could see their operation under threat. They began to compile their own figures of registrations, use etc. However, our own research did not confirm their figures, or at least their interpretation of them. For example, by contacting registered schools we found that many did so 
merely to get the materials and to tape the programs, much of which was not used. The Department's own evaluation then presented another view that was essentially negative in terms of the viability and feasibility, even if the programs were seen to be generally of high quality.

In essence our research was showing that for the primary schools at least, there was some really good use being made of SOFNet in the few schools that used it. The issue was were these schools just aberrations or was there something to understand from how they used it so successfully? As some of these primary schools were small rural primary schools the government was nervous about reducing their provision, not only on the grounds of equity, but also on the grounds that the social, economic and welfare decline in rural and regional areas was becoming (and remains) a matter of voters' concern.

As for the immediate future, SOFNet is currently in the midst of its fifth name change to Schools' Television hence removing any reference to the now defunct Schools of the Future. Interactive television as an innovative classroom technology and as a regular curriculum provision medium no longer exists and attempts are being made to utilise the network in other ways. The managers are attempting to generate more interest and greater usage of the network by other government departments and agencies; and the Director of Schools has committed to presenting a monthly interactive program for school principals commencing March 2001. A new producer is to be hired and the department's web-site redeveloped over the coming months to better reflect the current state of the World Wide Web.

As we complete this article it is unclear what will finally happen to SOFNet. Certainly, it has been further diminished and is losing even the schools which were committed users. Our research showed that, for those schools who made a commitment, there was a strong benefit for them and they were able to build a real strength around the use of SOFNet. It is also clear that for many schools the difficulties of working with SOFNet's scheduling, for example, was a hurdle they were not prepared to leap. This has contributed to a view in the schooling community that SOFNet is not workable and so it is never considered for use. It is probably this reality which will lead to the demise of SOFNet. However, it is a moot point to know whether, if SOFNet had been implemented differently, particularly with respect to its administration shortfalls, more schools would have used it and there may have been a stronger schooling community commitment to SOFNet. 
Interactive Television in Schools: An Australian Study of the Tensions of

\section{References}

Aliani, R. (1995). Primary and secondary access to languages via satellite (PALS \& SALS) projects. In Planning, practice and participation: Conference papers of the Second AFMLTA National Primary LOTE Conference, Melbourne: Modern Language Teachers Association of Victoria Inc.

Bates, A.W. (1984). Broadcasting in education. London: Constable.

Crooks, B. (1990, March). The potential of non-broadcast television technologies for learning and the implications for educational television design and research. Broadcasting Research in the Nineties Conference, Tel Aviv, Israel.

Evans, T. D., Stacey, E. \& Tregenza, K. (1999a, May). Investigating teaching and learning in schools through interactive television. A paper presented at the Computers in Education Conference, Melbourne, Victoria.

Evans, T. D., Stacey, E. \& Tregenza, K. (1999b, June). An investigation of the development of dialogic approaches to teaching and learning in schools through ITV. Refereed paper presented at Ed-Media, the Association for Advancement of Computing in Education conference, Seattle, WA.

Evans, T. D., Stacey, E. \& Tregenza, K. (1999c). Interactive television in primary schools: teachers' approaches to enhancing classroom based learning. In Collected papers from the 14th Biennial Forum of the Open and Distance Learning Association of Australia. Open, Flexible and Distance Learning: Challenges for the new Millennium, (pp.111-118). Deakin University: Geelong.

Evans, T. D., Stacey, E. \& Tregenza, K. (1999d, November). Interactive television in primary schools: Children's experiences of learning with SOFNet. Australian Association of Research in Education conference, Melbourne.

Evans, T. D., Stacey, E. \& Tregenza, K. (2000a). Selective summary and recommendations on the use of SOFNet in schools during the period 1998-early 2000. A report prepared for the Victorian Government Department of Employment Education and Training senior staff.

Evans, T. D., Stacey, E. \& Tregenza, K. (2000b, December). Close encounters in distance education: Research issues from case-study research on interactive television in schools. Paper presented at the Research in Distance Education Conference, Deakin University, Geelong.

Evans, T. D. \& Tregenza, K. (1993). Interactive television for teachers' professional development: Some preliminary findings. A paper presented at the Research in Distance Education 1993 seminar, Deakin University.

Evans, T.D. \& Tregenza, K. (1996a, May). Issues from three case-studies of International Review of Research in Open and Distance Learning 
Interactive Television in Schools: An Australian Study of the Tensions of

the use of interactive television in Victoria, Australia. A paper presented at the Canadian Association of Distance Education conference, University of Moncton.

Evans, T.D. \& Tregenza, K. (1996b, November). Schools and SOFNet: Findings from a case-study project on the use of interactive television in three Victorian Schools. A paper presented at the Australian Association for Research in Education Conference, Singapore.

Haughey, M. \& Roberts, J. (1996). Canadian policy and practice in open and distance schooling. In T.D. Evans, \& D.E. Nation, (Eds.), Opening education: Policies and practices from open and distance education (pp. 63-76). London: Routledge,.

McMillan, R. (1994). Some keys to unlocking learning with television. In M.S. Parer (Ed.), Unlocking open learning, Centre for Distance Learning, Distance Education Centre, (pp.107-119). Monash University: Churchill.

Meisalo, V. (Ed.). (1996). The integration of remote classrooms. Helsinki, FI: Dept. of Teacher Education, University of Helsinki.

Victorian Department of Education (1997). What is SOFNet?: Victorian Department of Education satellite TV (Video). Department of Education, Melbourne, Victoria.

International Review of Research in Open and Distance Learning 
Interactive Television in Schools: An Australian Study of the Tensions of Educational Technology and Change

\section{Endnotes}

1. 1993 Australian Research Council funded project, An investigation of teachers' professional development by satellite broadcast interactive television in rural schools. Terry Evans was the Chief Investigator on the project with Karen Tregenza as the Research Associate. 1995 - 96 Deakin University funded project, Two case studies of the impact of interactive television (ITV) on school cultures and practices. Terry Evans was the Chief Investigator on the project with Karen Tregenza as the Research Associate. 1998 - 2000 Australian Research Council funded project, An investigation of the development of dialogic approaches to teaching and learning in schools through ITV. Terry Evans and Elizabeth Stacey were the Chief Investigators on the project with Karen Tregenza as the Research Associate.

2. The implementation of the research and its analysis has been discussed by the authors previously (Evans, Stacey \& Tregenza, 2000b).

Citation Format

Evans, Terry, Stacey, Elizabeth \& Tregenza, Karen (July, 2001) Interactive Television in Schools: An Australian Study of the Tensions of Educational Technology and Change. International Review of Research in Open and Distance Learning: 2, 1.

http://www.icaap.org/iuicode?149.2.1.6

International Review of Research in Open and Distance Learning 